\title{
GENÉTICA Y FORMACIÓN CIENTÍFICA: RESULTADOS DE UN PROYECTO DE INVESTIGACIÓN Y SUS IMPLICACIONES SOBRE LOS PROGRAMAS ESCOLARES Y LA ENSEÑANZA*
}

WOOD-ROBINSON, C. ${ }^{1}$, LEWIS, J. ${ }^{1}$, LEACH, J. y DRIVER, R. ${ }^{2}$

${ }^{1}$ Learning in Science Research Group, Centre for Studies in Science and Mathematics Education. Universidad de Leeds. Reino Unido.

2 King's College. Universidad de Londres. Londres. Reino Unido.

\section{SUMMARY}

This paper discusses the place of genetics in the context of scientific literacy and the school science curriculum. It then goes on to report on the work of a three year research project which seeks to document the understanding of genetics, and of modern genetic technologies, and opinions of these technologies among 15.16 years olds in England. Four aspects of the work will be reported on here. These are concerned with understanding the genetics of cells, the universality of genetic information among living things, and gene technology, and with opinions on the advisability of prenatal screening for cystic fibrosis. The implications for the school curriculum and for teaching are then discussed. The authors are grateful to the Wellcome Trust for their support in enabling this research.

\section{INTRODUCCIÓN. «LA NUEVA GENÉTICA»}

En Ios últimos años, ha habido un rápido incremento en el desarrollo de un conjunto de tecnologías genéticas. Están apareciendo en los mostradores de los supermercados alimentos, tales como el queso, la salsa de tomate y una serie de productos que contienen harina de soja o aceite de soja, derivados de organismos modificados genéticamente. Productos farmacéuticos como la insulina y las hormonas del crecimiento, producidos por bacterias modificadas genéticamente, son de uso diario. La creación de animales transgénicos ha incrementado todavía más la disponibilidad de una serie de sustancias terapéuticas. La terapia somática con genes está siendo experimentada en el tratamiento de desórdenes genéticos tales como la fibrosis cística, la deficiencia de adenosina desaminasa (SCID) y la hemofilia. La identificación por huella de $\mathrm{ADN}$ se ha convertido en una herramienta corriente en la detección de crímenes. Ha sido secuenciado el genoma completo del primer euca- riota (Saccharomyces cerevisiae) y Ios trabajos del Proyecto del Genoma Humano mantienen su objetivo de conseguir la secuenciación del genoma humano completo para fin de siglo. Los medios de comunicación han prestado atención al seguimiento de todos estos desarrollos a través de la creación de una oveja transgénica y del papel de la identificación por huella de $A D N$ en juicios criminales ampliamente difundidos, convirtiéndose en noticias de primera plana en el Reino Unido. Estas nuevas tecnologías suscitan numerosos interrogantes sociales y éticos.

- ¿Hasta qué punto es legítimo modificar los genomas de las plantas para crear un alimento «mejorado» para el consumo humano?

- Si es legítimo para las plantas, ¿es también aceptable modificar mamíferos genéticamente? 
- ¿Quién debe decidir acerca de la disponibilidad del rastreo genético para las enfermedades y demás características hereditarias?

- ¿Quién es el propietario de la información obtenida de tales rastreos o huellas de ADN?

- ¿Cuál será el efecto sobre el medio ambiente si se liberan organismos modificados genéticamente?

- ¿Cuál será el efecto de la terapia genética sobre el acervo genético humano?

- ¿Quién debería tener el control sobre el desarrollo y uso de estas nuevas tecnologías?

Es adecuado destacar que los cultivadores de plantas y los criadores de animales hace siglos que vienen modificando los genomas de los organismos y rara vez se ha cuestionado su trabajo. Pero los experimentos que implican las tecnologías de manipulación del ADN se perciben de forma muy distinta -quizá debido a la transferencia de material genético de una especie de organismos a otra.

Hay también otra faceta de estos experimentos que es, quizá, más personal. Cada uno de nosotros tiene su propia y única dotación de $\mathrm{ADN}$, su propio conjunto particular de genes -o más correctamente de alelos, que no se comparten con nadie más excepto en el caso de gemelos monozigóticos. La manipulación de genes y las demás tecnologías asociadas con nuestra estructura genética son, por tanto, muy importantes para todos y cada uno de nosotros.

Los jóvenes escolares de hoy en día, cada vez más, forman parte de una sociedad en la que éstas y otras tecnologías genéticas son hechos cotidianos. Se les exigirá que tomen decisiones personales relacionadas con los resultados de estas tecnologías y algunos de ellos se convertirán en elementos decisorios que tendrán influencia sobre las actitudes sociales respecto a estas y a otras cuestiones conexas. Sin embargo, tenemos un conocimiento escaso tanto del nivel de comprensión que la población juvenil tiene de la genética moderna como de sus opiniones y actitudes frente a las cuestiones suscitadas por los trabajos en este campo. Las evidencias presentadas al Comité de Ciencia y Tecnología de la Cámara de los Comunes del Reino Unido (House of Commons, 1995) sugerían que la comprensión de la genética mostrada por el público corriente es muy baja. Es probable que el conocimiento y comprensión de los jóvenes, y sus opiniones y actitudes, se deban en parte a la enseñanza formal en las escuelas, pero también a una serie de distintas fuentes provenientes de los medios de comunicación y de otros orígenes. Es contra este trasfondo cómo se inició el proyecto de investigación presentado aquí.

En este informe se considera la lógica de esta investigación en el contexto de la enseñanza de la genética enfocada hacia la alfabetización científica. En él se examina, el lugar que corresponde a la genética dentro del Currículo Nacional de Ciencias en el Reino Unido, antes de enmarcar las cuestiones de investigación que el proyecto pretende abordar. Se destacan algunos de los resultados del estudio. $\mathrm{Y}$, finalmente, consideramos algunas implicaciones de los hallazgos para el currículo de ciencias y para la enseñanza.

\section{EDUCACIÓN GENÉTICA Y FORMACIÓN CIENTIFICA}

A la educación científica se le concede una alta prioridad en muchos países y, a menudo, se considera importante que se preparen científicos y técnicos con el fin de contribuir a las economías nacionales. Uno de los métodos para garantizar una provisión adecuada de profesionales bien preparados sería el de seleccionar los estudiantes más capacitados durante las primeras fases de su educación y ofrecerles unos programas especializados en ciencias. Sin embargo, los objetivos de los currículos de ciencias en el mundo tienden a una mayor amplitud de miras y son pocos los países que han adoptado políticas educativas tan restrictivas. Además de proporcionar especialistas altamente cualificados, uno de los objetivos declarados de los currículos de ciencias en muchos países consiste en promocionar la formación científica para todos los estudiantes como parte de su educación general (American Association for the Advancement of Science, 1989; National Curriculum Council, 1993; Royal Society, 1985; European Union, 1993).

Aunque la promoción de la formación científica se explicita frecuentemente como objetivo de la educación científica en los documentos políticos públicos, se presta poca atención a la hora de definir qué formación científica debe considerarse, o qué debe ser capaz de poder hacer una persona cientifficamente formada. No obstante, en la literatura de didáctica de las ciencias se han caracterizado algunos tipos de formación científica distintos, dependiendo de la manera según la cual los individuos aplican y utilizan su conocimiento científico para propósitos concretos (una discusión profunda acerca de estos temas puede encontrarse en Driver et al., 1996).

La utilización de los conocimientos científicos con fines utilitarios implica que los individuos apliquen de una forma práctica los conocimientos científicos que les resulten útiles. Un ejemplo de ello sería la aplicación de los conocimientos acerca de la teoría de los gérmenes de las enfermedades para prevenir la contaminación en el proceso de preparación de alimentos.

La utilización de los conocimientos científicos con fines democráticos implica que los individuos apliquen sus conocimientos para entender y participar en los debates relacionados con temas científicos. Los individuos necesitan un cierto grado de conocimientos científicos para abordar la ciencia y la tecnología tal como se presentan en la sociedad moderna. En todas las sociedades modernas, deben tomarse decisiones acerca de cuestiones que tienen una dimensión científica, tales como la forma en que debe generarse y utilizarse la energía, 
cómo debemos deshacernos de los residuos, cómo debe maximizarse la salubridad de los alimentos, etc.

Además, la formación científica de tipo cultural implica que los individuos entiendan la ciencia como un logro cultural de la sociedad moderna. El arte, la música y la literatura han dado pasos de gigante durante el siglo XX. Sería lógico que consideráramos como culturalmente empobrecidos a los jóvenes españoles a los que la escuela no hubiera enseñado los logros obtenidos este siglo por Pablo Picasso, Federico García Lorca y Manuel de Falla. Su educación estaría igualmente desajustada si no se les hubiera hecho conscientes del aumento de nuestra comprensión de la genética por las aportaciones de trabajadores como Watson y Crick, Jacob y Monod, y muchos otros, a lo largo de las últimas décadas.

Estas caracterizaciones de la formación científica sirven para delinear los diferentes modos en que el conocimiento científico puede aplicarse en diferentes situaciones. No obstante, está lejos de ser evidente la forma en que el currículo escolar de ciencias puede ayudar a la formación científica por estos propósitos. Consideremos el caso utilitario. ¿Se puede diseñar un currículo escolar de ciencias para que pueda equipar a todos los individuos con los conocimientos científicos que pueden Ilegar a necesitar en los diversos contextos personales y profesionales durante el resto de sus vidas? En cierto sentido, es evidente que no, puesto que el desarrollo del conocimiento durante los próximos sesenta años (la vida futura de los graduados escolares de hoy) es desconocido e impredecible. Y sesenta años atrás, por ejemplo, todavía no se había demostrado, ni tan siquiera, que el ADN fuera el material genético que controlaba la síntesis de las proteínas. Para la propuesta de Watson y Crick de estructura de doble hélice para el ADN faltaban aún veinte años. ¿Quién, en aquel tiempo, podría haber predicho el desarrollo de nuestra comprensión del papel del ADN o -incluso más- quién podía haber intuido el desarrollo de la tecnología deI ADN brevemente mencionada anteriormente? Por consiguiente, ¿cómo puede la ciencia escolar preparar a los estudiantes de hoy para los desarrollos que pueden tener lugar? Hay, además, una argumentación que indica que los individuos necesitan muy poca comprensión conceptual de la ciencia para manejar los artefactos científicos y tecnológicos; por ejemplo, los electricistas no necesitan aplicar conocimientos formales acerca de la corriente eléctrica y de la diferencia de potencial para hacer el cableado en un edificio.

Un razonamiento similar puede aplicarse al caso democrático. ¿Cómo puede diseñarse un currículo escolar de ciencias para que dote a los individuos de la amplitud adecuada de conocimientos científicos que les permitan abordar los temas con los que pueden encontrarse en su futura vida adulta? Incluso los expertos se muestran a menudo prudentes a la hora de expresar opiniones sobre cuestiones que se salen de sus propias especialidades (Millar, 1996).

Un programa de ciencias que aspire a promover la comprensión del significado cultural de la ciencia po- dría diseñarse de forma muy distinta y centrarse en hechos históricos clave, tales como la revolución copernicana, la aparición de la teoría evolutiva o de «la revolución del $\mathrm{ADN}$ » iniciada por Watson y Crick hace cuarenta años. Sin embargo, tales temas no quedarían necesariamente incluidos en un currículo diseñado con fines utilitarios o dernocráticos. Pero, podría argumentarse que un currículo de ciencias diseñado con fines culturales no sería tan diff́cil de preparar como otros diseñados con fines utilitarios o democráticos.

Turney (1995) ha sugerido tres motivos principales para desarrollar la comprensión de la genética entre la gente. En cierto modo, estos motivos se solapan con la clasificación utilitario, democrático, cultural a la que ya nos hemos referido. El primer motivo de Turney está relacionado con la necesidad que tienen los individuos de ser capaces de dar su consentimiento documentado, y también de ser capaces de interpretar los resultados de la multitud de pruebas de rastreo que teóricamente estarán disponibles conforme se acerca la culminación del trabajo del Proyecto del Genoma Humano. Ésta es, claramente, una justificación utilitaria. La segunda razón se relaciona con la necesidad de una más completa comprensión con el fin de apoyar en este campo determinadas políticas. Finalmente, hay un deseo por parte de los investigadores de que el público esté mejor informađo con el fin de que valore sus investigaciones, permita que continúen y las subvencione. La regulación y supervisión de los trabajos de investigación en este campo debe realizarse en un clima de información, en vez de hacerlo en un clima de ignorancia. Tales razones democráticas para una comprensión pública de la ingeniería genética ya se esgrimieron hace veinte años por el senador Edward Kennedy cuando sugirió que «la evaluación del riesgo y la valoración de cómo equilibrar el riesgo y el beneficio de la investigación sobre el ADN recombinante son responsabilidades que atañen claramente al dominio público. Y por consiguiente, estos asuntos deben decidirse a través de procesos públicos» (Dutton, 1984, citado por Michie et al., 1995).

Siguiendo el primer motivo de Turney, los organismos de la salud pública constituyen quizá el área más probable en el que las gentes se van a encontrar, de entrada, con las nuevas tecnologias genéticas en aspectos que pueden afectarles profundamente. Cada vez más, se va a poder ofrecer a la gente el rastreo de diversas condiciones genéticas antes de iniciar una familia, o durante el embarazo, o quizá incluso antes del matrimonio. Para decidir si aceptar la oferta de un rastreo, y para decidir cómo actuar a resultas de la informacion obtenida de tal rastreo, los individuos tendrán, probablemente, que decidir no sólo a partir de lo que han entendido como resultado de su relacion con los especialistas (consejeros genéticos, administradores del rastreo, auxiliares médicos, etc.) sino también a partir de sus propios conocimientos de genética.

Los procesos mediante los cuales los humanos seleccionan y aplican sus conocimientos en contextos particulares son, en cualquier caso, muy complejos. La gente identifica los aspectos destacados de una situación a 
partir de un conjunto de posibilidades, decide qué conocimiento puede resultar relevante para esa situación, posiblemente busca más información y, finalmente, alcanza una decisión. Consideremos una situación en la que esté implicada la genética: una pareja está esperando un niño. Ambos han resultado positivos en una prueba como portadores de fibrosis cística y, en consecuencia, se les ofrece un rastreo prenatal para tener mayor conocimiento del estado de fibrosis cística de su feto.

Entender algunos de los aspectos importantes de este caso implica diversas dimensiones:

- ciertos conocimientos de genética básica;

- una apreciación de la fiabilidad y de los riesgos de esta forma de rastreo prenatal;

- una comprensión de la prognosis probable de los niños nacidos con fibrosis cística;

- una previsión documentada de las futuras posibilidades del desarrollo de la terapia genética y de otros tratamientos.

Otros aspectos de la situación se relacionan más con los compromisos éticos y con las prioridades personales. Por ejemplo, algunas parejas podrían tener que tomar en consideración sus propias actitudes respecto a la salud y al aborto, a la vista de la situación.

El ejemplo anterior es complicado: ¿Cómo podría un individuo «científicamente formado» arreglárselas para alcanzar una decisión? No parece tener sentido hablar de alcanzar decisiones «racionales» basadas en la aplicación «adecuada» de conocimientos científicos «relevantes». Las prioridades personales de los distintos individuos son distintas. Por consiguiente, es lógico esperar cierta diversidad en el abanico de prioridades y en la aplicación de los conocimientos por parte de distintas personas. Por otro lado, a todas las parejas en tal situación se les proporcionaría una información muy similar sobre las condiciones de la fibrosis cística, de la naturaleza de su herencia y del proceso de rastreo. Las parejas estarían, por tanto, en la coyuntura de tener que interpretar la información suministrada y de decidir qué es relevante en su situación y qué no. En tal tesitura, los individuos con cierta base de conocimientos acerca de la naturaleza de la herencia y de la enfermedad genética estarían en mejor posición que aquéllos que no tuvieran tales conocimientos para entender la información suministrada.

No resulta realista esperar que los currículos escolares de ciencias incluyan información detallada acerca de todas las enfermedades genéticas conocidas. Además de otros condicionamientos, la lista de las situaciones que tienen un componente genético se está ampliando continuamente. Durante el último año aproximadamente, el cáncer de mama, la enfermedad de Alzheimer y la enfermedad de Parkinson han sido identificadas, al menos en parte, como transtornos de origen genético. Por tanto, un objetivo más realista para el currículo escolar de ciencias podría consistir en dotar a todos los jóvenes de una serie de conocimientos científicos más básicos, junto con cierta comprensión del tipo de situaciones en las que tales conocimientos puedan resultar útiles. Pero vale también la pena destacar que se conoce muy poco acerca de cómo utiliza y aplica la gente las diversas formas de conocimiento en contextos problemáticos que tienen una dimensión científica (véase Layton et al., 1993). Esperemos que nuestra investigación actual ayude a proyectar cierta luz sobre este asunto.

Los temas que surgen de la aplicación de la tecnología genética pertenecen plenamente al contexto científico. Volvamos al ejemplo del rastreo prenatal de una enfermedad genética. La fibrosis cística es un estado que afecta a los que la sufren desde el nacimiento, dando lugar normalmente a una infancia y una adolescencia difíciles y a una muerte prematura -habitualmente durante la primera edad adulta. A las parejas que aceptan las ofertas de rastreo prenatal y que descubren que su futuro hijo tendrá, o podría tener, fibrosis cística podría ofrecérseles la posibilidad de abortar. Sin embargo, en el caso de enfermedades genéticas diferentes pueden presentarse cuestiones completamente distintas. Las personas con la enfermedad de Huntington, por ejemplo, normalmente no presentan ningún síntoma hasta alrededor de los cuarenta años. Las cuestiones relacionadas con la conveniencia del rastreo prenatal de la fibrosis cística y de la enfermedad de Huntington son, por consiguiente, muy diferentes. Utilizaremos el término cuestión para indicar cualquier materia que surja a partir de un contexto determinado y que potencialmente implique que se tome una decisión. Como parte de nuestra investigacion, nos interesan las cuestiones que los jovenes identifican como resultado de contextos determinados que se relacionan con la «nueva genética», y las formas en que interpretan la informacion que dichas cuestiones comportan.

La gente puede formarse opiniones acerca de cuestiones específicas que surgen en contextos determinados. Utilizaremos el término opinión para indicar una postura adoptada por principios morales y relativa a cuestiones determinadas en contextos concretos. Por ejemplo, alguien puede formarse la opinión de que el aborto de los fetos con fibrosis cística es inaceptable. Usaremos el término actitud para referimos a posturas adoptadas por principios morales de carácter más general. Algunos individuos, por ejemplo, pueden tener la actitud de que el aborto es éticamente exróneo en cualquier circunstancia. Naturalmente, no siempre es posible saber si una postura explícita debida a principios morales es particular de un contexto concreto o es más general.

Para facilitar tanto el desarrollo del currículo como el de Ia ensefianza en el Reino Unido, para alcanzar los objetivos discutidos antes, es esencial la información empí rica acerca de los puntos de partida de los estudiantes en temas determinados de áreas curriculares, tales como la genética. En nuestra investigación estábamos interesados en profundizar más acerca del tipo de conocimiento genético que tienen los jóvenes al final đe su educación científica obligatoria y acerca de su conocimiento sobre 
la gama de aplicaciones de la tecnología genética. Con ello tendríamos una idea del tipo de conocimiento que podría estar đisponible para su aplicación futura con el fin de entender cuestiones concretas que tengan un contenido genético. Solamente contando con esta información bien documentada acerca de los conocimientos y comprensión actuales de los estudiantes sobre la gentética y sobre sus percepciones de las cuestiones que surgen a partir de las tecnologías genéticas y de sus opiniones acerca de ellas, podemos empezar a abordar de forma significativa determinadas cuestiones acerca del diseño curricular y la pedagogía.

Hay otro punto que es necesario plantear: Admitimos que la relación entre cómo responden a las preguntas los estudiantes en el contexto de las encuestas escolares y cómo pueden reaccionar los mismos individuos ante decisiones de la vida real que les afecten personalmente puede llegar a ser muy tenue.

Vale la pena insistir en que ha habido un volumen considerable de investigaciones ya publicadas en el campo de la comprensión que los niños tienen acerca de la herencia, pero generalmente no se ha insistido en la genética. Nosotros queremos distinguir la herencia como Ia adquisición de características de un individuo a través de la transferencia de material a partir del (los) progenitor (es) de dicho individuo, por contraste con la genética, que es no sólo el estudio de las pautas hereditarias, sino que se ocupa también de mecanismos tales como la forma en que se transfieren esas características y la forma en que se expresan los genes. Informes a propósito de las investigaciones sobre la comprensión de los jovenes acerca de la herencia pueden encontrarse en WoodRobinson (1994, 1995).

\section{GENÉTICA Y EL CURRÍCULO NACIONAL DE CIENCIAS DE INGLATERRA Y DE GALES}

Todos los estudiantes de las escuelas públicas de Inglaterra y Gales ${ }^{1}$ siguen un curso de ciencias definido por un Currículo Nacional. En él se incluyen, dentro de un Programa de Estudio, elementos de genética que se abordan en los niveles de enseñanza secundaria denominados «Etapa clave 3" (para estudiantes de edades entre I1 y 14 años) y «Etapa clave 4» (para estudiantes de edades entre 14 y 16 años). Para los dos últimos años de enseñanza obligatoria ( $E$ Etapa clave $4 \%$ ), este curso puede adoptar la forma de un curso de ciencias sencillo o de un curso de ciencias doble, lo que lleva a la obtención de un diploma de asignatura simple o doble en el Certificado General de Educación Secundaria. El estudio hasta este nivel constituye, por tanto, la educación cientifica obligatoria que van a recibir, presumiblemente, todos los miembros de la población. En el momento de nuestra investigación, todos los estudiantes de la "Etapa clave 4» estaban cursando ciencias según el Currículo Nacional (Department of Education and Science, 1991). Las secciones relevantes para la genética se muestran en el apéndice I.
Nuestro Currículo Nacional es bastante explícito en cuanto a lo que exige que se enseñe a los estudiantes. Sin embargo, algunos aspectos de Ia genética básica más que aparecer de forma explícita quedan implícitos en dicho currículo. Hay también algunas exigencias de enseñanza explícita acerca de cuestiones más relacionadas con la formación científica. Surgen algunos interrogantes sobre lo que queda implícitamente incluido bajo los diversos elementos establecidos en el Programa de Estudio. Por ejemplo, ¿cómo deben abordarse las variaciones de la información genética entre los gametos de un individuo concreto? Aparte de proporcionar algunos ejemplos, no se dan indicaciones sobre ningún tipo de método de enseñanza y los profesores tiene que decidir por sí mismos a este respecto. Básicamente, en términos de transferencia de información genética, falta una mención explícita sobre la relación entre genes y cromosomas y sobre la importancia de esta relación en la transferencia de la información genética de célula a célula y de individuo a individuo.

También se pueden poner en cuestión otros aspectos implícitos de los requisitos formales:

- ¿Necesitan los estudiantes ser conscientes de que los genes están dispuestos en los cromosomas, que normalmente están dentro de núcleos contenidos en células que constituyen los organismos?

- ¿Deberían, por tanto, ser capaces de ordenar los términos célula, cromosoma, gen, $A D N$, organismo, núcleo en una secuencia lógica según su tamaño?

- ¿Deberían entender, los estudiantes, que la informaciốn genética de todos los núcleos de células somáticas de un organismo dado es la misma, pero que se interpreta y se utiliza de forma distinta en las células de distintos tejidos?

- ¿Necesitan entender, los estudiantes, los resultados globales de una división meiótica que da lugar a óvulos y espermatozoides que tienen el número haploide de cromosomas?

- ¿Necesitan incluso saber de la existencia de cromosomas, que no se mencionan específicamente en el Currículo Nacional excepto mediante ejemplos?

- ¿Deberían conocer el término alelo o basta con la idea de que un gen puede existir en más de una forma? (Obsérvese que alelo se utiliza específicamente en una de las «Formulaciones de Objetivos de nivel 8» del Currículo Nacional).

Éstas son preguntas que los profesores deben tomar en consideración como base habitual al preparar sus clases. Nosotros sostenemos que hay muchos aspectos de la genética que están implícitamente incluidos en los diversos elementos del Currículo Nacional y varios de ellos constituyen, lógicamente, la base de nuestra investigación.

Vale la pena destacar que existe un requisito legal para que las escuelas de Inglaterra y de Gales cubran el 
Programa de Estudio. Nuestro Currículo Nacional incluye también «Formulaciones de Objetivos» establecidas en diversos niveles que no se espera que sean alcanzados por todos los estudiantes cuando dejen la escuela -es más, solamente los estudiantes excepcionales alcanzarắn el nivel 10, eI más alto. En ese nivel deberían, por ejemplo, entender cómo se duplica el ADN, o entender los principios básicos de la ingeniería genética. Pero el Programa de Estudio deja muy claro que los estudiantes «deberian [...] estudiar cómoes capaz el ADN de autoduplicarse» y «deberían tener la oportunidad de considerar los principios básicos de la ingeniería genética». Por consiguiente, hay un requisito legal para que se enseñen en Ia escuela estos elementos a todos los estudiantes, aunque no todos esos estudiantes adquirirán necesariamente esa comprensión.

Hay también aspectos obvios pero importantes de la genética que quedan excluidos de nuestro Currículo Nacional. La herencia poligénica o multifactorial es un ejemplo, de lo que puede ser considerado como implícito en esta área -el color de ojo en los humanos es utilizado como ejemplo. No es éste el lugar para comentar la conveniencia de un curso de ciencias de este nivel que no incluya explícitamente un concepto tan trascendental.

\section{LA COMPRENSIÓN DE LOS JÓVENES Y SU ACTITUD SOBRE EL PROYECTO DE INVESTIGACION «LA NUEVA GENETICA»}

Con estos antecedentes informaremos acerca de un proyecto de investigación que se ha realizado dentro del Grupo de Investigación sobre el Aprendizaje de la Ciencia (Learning in Science Research Group) de la Universidad de Leeds, desde 1994. El proyecto ha sido financiado por el Wellcome Trust y culminará sus trabajos hacia finales de 1997.

El proyecto ha abordado los cuatro interrogantes principales de investigación que surgieron a partir de una consideración del papel de la genética en la comprensión pública de la ciencia y a partir de la agenda establecida por nuestro Currículo Nacional de ciencias. Estas preguntas determinaron la dirección de la investigación.

- ¿Qué conocimientos y comprensión tienen los jóvenes sobre la genética al final de los años de escolaridad obligatoria?

- ¿Qué conocimientos y comprensión tienen esos mismos jóvenes sobre las nuevas tecnologías genéticas?

$-¿$ Qué cuestiones perciben que han sido suscitadas por la aplicación de las nuevas tecnologías genéticas en contextos determinados?

- ¿Qué opiniones y actitudes toman esos jóvenes respecto a la aplicación de esas tecnologías?

No es éste el lugar para discutir en detalle el diseño y la metodología de estudio. Tal cuestión se desarrolla en
Wood-Robinson y otros (1996) y en diversos informes de trabajo del proyecto, algunos ya publicados y otros en preparación. Pero querríamos discutir algunos de los hallazgos y sus implicaciones para los programas de ciencias y para su enseñanza.

Al diseñar nuestros instrumentos de investigación tuvimos en cuenta no solamente los requisitos explícitos e implícitos del Currículo Nacional sino también aquellos aspectos de la genética que consideramos que eran importantes como trasfondo para la comprensión de «la nueva genética». Estos aspectos se esquematizan en el apéndice 2. Aplicamos cuatro métodos distintos para recoger datos a partir de una muestra de 743 estudiantes - la mayoría de los cuales estaba en su último año de enseñanza obligatoria y había seguido el Currículo Nacional de ciencias, incluyendo aquellos elementos relevantes para la genética:

- 11 preguntas de papel y lápiz, a las que llamamos sondeos, contestadas individualmente por los estudiantes.

-6 sondeos de papel y lápiz, contestados individualmente por los estudiantes, pero solamente después de haberlos discutido con otro estudiante.

- 3 tareas de discusión en las que cuatro estudiantes hablaban e intercambiaban ideas con un investigador. Dos de estas tareas se centraban en cuestiones sugeridas por el investigador, y la tercera sondeaba los conocimientos y la comprensión. La discusión se registraba en cinta y se transcribía antes de proceder a su análisis.

- 12 declaraciones de actitud contestadas individualmente por los estudiantes en una escala de tipo Lickert.

Vamos a dar aquí los resultados de tres sondeos de la primera categoría y de una de las tareas de discusión.

\section{COMPRENSIÓN DE LA INFORMACIÓN GENETICA DE LAS CELULAS}

Parte de uno de los sondeos de papel y lápiz-llamado Células - estaba diseñado para investigar la comprensión de los estudiantes de la naturaleza y del papel de la información genética en cuatro pares diferentes de células del mismo individuo:

- dos células somáticas del mismo tipo (células epiteliales de la cavidad bucal);

- dos células somáticas de distinto tipo (una célula epitelial de la cavidad bucal y una célula nerviosa);

- una célula somática (célula de la cavidad bucal) y una célula germinal (espermatozoide);

- dos células germinales (espermatozoides).

Así, el sondeo estaba diseñado para explorar si los estudiantes eran o no conscientes de que la información 
genética de todas las células somáticas del mismo individuo es la misma -aunque se utilice de diferente forma en las distintas células. El sondeo estaba también diseñado para evaluar la comprensión de las diferencias esenciales entre la información genética de las células somáticas y de las células germinales, y la variación de la información genética en células germinales distintas.

Los estudiantes dieron explicaciones razonadas que fueron agrupadas en tres niveles distintos, según tres puntos de partida diferentes. Estos puntos de partida se resumen en la figura 1. Puede verse que la mayoría de los estudiantes sostuvo la opinión de que las células del mismo tipo son genéticamente idénticas, pero que los distintos tipos de células contienen información genética distinta. Proporciones mucho menores de estudiantes creían, o bien que cada célula es distintivamente única, o bien que todas las células -incluidas las células germinales- son iguales. Más del $60 \%$ de nuestra muestra se adscribía a uno de estos tres puntos de partida en su razonamiento. Solamente alrededor del $7,5 \%$ de nuestra muestra sostuvo Ia idea cientúfica de que todas las células somáticas son genéticamente idénticas y que las células espermáticas son distintas -tanto de las células somáticas como de las demás. Estos hallazgos fueron también confirmados por las tareas en pequeños grupos en los que un investigador discutía sobre la información genética de las células con grupos de cuatro estudiantes.

En Lewis y otros (en preparación) y en Wood-Robinson y otros (en preparación) se dará un informe más detallado acerca de la comprensión de los estudiantes de la genética de Ias células.

Figura 1

La comprensión de los estudiantes de la naturaleza de la información genética de las células.

$\begin{array}{ll}\text { Puntos de } & \text { Todas las células tienen la } \\ \text { partida } & \text { misma información genética }\end{array}$

$11 \%$

Diferenciación
de las células
somáticas y
germinales

Comprensión científica

Todas Ias células somáticas tiene la misma información genética. Todas las células germinales tienen la misma información genética. Las células somáticas tienen distinta información genética que las germinales

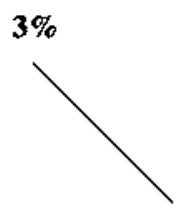

Todas las células del mismo tipo tienen la misma información genética. Cada tipo de celula tiene distinta información genética

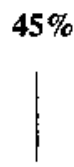

Cada célula es diferente de todas las demás
Cada tipo de célula tiene información genética diferente de todos los demás tipos. Cada célula tiene información genética diferente del resto de las células germinales
$8 \%$

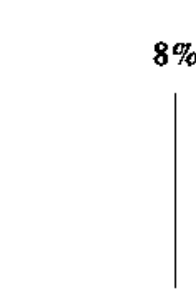

Todas las células somáticas tienen información genética distinta. Todas las célutas germinales tienen la misma de la de las células somáticas información genética, distinta

Todas las células somáticas tienen la misma información genética.

Cada célula germinal tiene información genética distinta del resto de las células germinales.

Las células germinales tienen información genética distinta de las somáticas

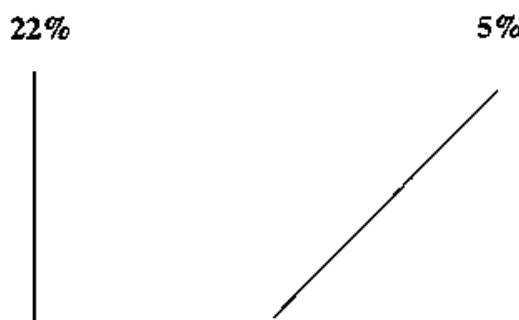

\section{$\%$}

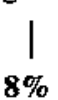




\section{COMPRENSIÓN DEL PAPEL DE LAS CÉLU- LAS, DE LOS CROMOSOMAS Y DE LA IN. FORMACION GENETICA EN LOS SERES VIVOS}

El sondeo Seres vivos se diseñó para investigar si los estudiantes eran conscientes de:

- la variedad de los seres vivos;

- la relación entre las células y todo el organismo;

- la relación entre los cromosomas y la información genética;

- el hecho de que, mientras no todos los organismos contienen cromosomas, todos los organismos si que contienen información genética.

Se formuló a los estudiantes una serie de preguntas de respuesta prefijada acerca de siete grupos diferentes de organismos: árboles, mamíferos, helechos, virus, hon. gos, bacterias e insectos.

Las preguntas fueron:

1) ¿Has oído hablar de estos organismos?

2) ¿De cuántas células crees que está compuesto cada uno de estos organismos?

\section{3) ${ }_{6}$ Contienen estos organismos cromosomas?}

\section{4) ${ }_{6}$ Contienen información genética?}

Se eligieron esos tipos de organismos para reflejar un abanico de seres vivos. Se incluyeron tanto organismos eucarióticos (árboles, mamíferos, helechos, hongos e insectos) como organismos procarioticos (bacterias) y virus. Si bien todos los seres vivos contienen informa. ción genética, ésta se organiza de modo distinto en esos diferentes grupos de organismos. Además, los eucariotas tienden a ser multicelulares, los procariotas suelen ser unicelulares y los virus carecen de estructura celular. Estas diferencias tienen implicaciones respecto a la utilidad de estos diferentes tipos de organismos en la tecnología genética y en las formas en que puede manipularse su material genético. El sondeo completo puede encontrarse en Lewis y otros (1997). Hubo 474 respuestas en este sondeo, que representan el $98,3 \%$ de los 482 estudiantes a los que se pidió que respondieran.

La comprensión del hecho de que todos los seres vivos contienen información genética es fundamental para una comprensión de la genética. El sondeo Seres vivos se proponía investigar acerca de la comprensión de los estudiantes sobre esta noción, examinando si mantenían visiones consistentes en toda una gama de organismos. Nuestra investigación preliminar sugería que existía cierta confusión entre gen y cromosoma, potenciada quizá por algunas partes del Currículo Nacional. Algunos estudiantes parecian pensar que eran términos sinónimos. Es importante comprender la relación entre ge- nes, cromosomas, células y la totalidad del organismo para entender cómo se transfiere la información genética y cómo afecta a la totalidad del organismo.

El que los estudiantes sean conscientes de estos puntos tiene implicaciones importantes, no solamente para su comprensión de las tecnologías genéticas y de la tecnología de ADN recombinante sino también para sus actitudes hacia Ias diversas apticaciones de estas tecnologías. Por ejemplo, los primeros tanteos indicaban que varios estudiantes tenían poca idea acerca de la escala relativa de las diferentes estructuras y, por consiguiente, tenían una imagen de la ingeniería genética que la situaba en una escala similar a la cirugía normal. Como resultado, les preocupaba que, si se utilizaban animales para tales trabajos, se les causaría dolor físico. Casi todos los estudiantes declararon en sus respuestas que habían oído hablar de árboles, mamíferos, bacterias e insectos, $y$ un porcentaje pequeño pero significativo afirmó que no habían oído hablar de hongos $(3 \%)$, virus $(7 \%)$ o helechos $(13,5 \%)$.

Los principales hallazgos a partir de las respuestas a este sondeo fueron:

- Se consideraba a los animales significativamente distintos de los otros organismos.

- Se consideraba a los insectos como similares a los mamíferos.

- Se consideraba la mayor parte de las formas de vida compuestas por células.

- No se consideraban que muchas formas de vida tuvieran ni cromosomas ni información genética.

- Los dos últimos puntos sugerían una confusión generalizada de la relación entre células y las estructuras y la información que ellas contienen.

En las respuestas a la pregunta « ¿ Cuántas células tiene este organismo?», los estudiantes parecían ser más conscientes de la naturaleza celular de los animales que de las plantas. 9 de cada 10 estudiantes dijeron que los mamíferos estaban compuestos de muchas células pero solamente 3 ó 4 creía lo mismo respecto a los árboles. Inversamente, el $7,2 \%$ pensaba que los árboles estaban compuestos de una sola célula, pero solamente un $3,6 \%$ pensaba lo mismo de los mamíferos. El 7,6\% pensaba que los árboles no contenían célutas en absoluto. Al considerar las respuestas sobre a los helechos, los hon" gos y los insectos, estas diferencias conceptuales en su percepción de los animales (mamíferos e insectos) comparada con el resto de los organismos eucarióticos resultaban ser consistentes.

Los estudiantes parecían tener una mejor comprensión de la naturaleza celular de las bacterias que de los árboles. Casi la mitad de las respuestas acerca de las bacterias decía que tenían una sola célula, lo cual contrastaba con el poco más de un tercio que decía que las bacterias tienen muchas células. Había también cierta 
conciencia de las diferencias entre las bacterias y los virus. Si bien un número similar pensaba que los virus tienen muchas células, un porcentaje algo más alto pensaba que no tienen células en absoluto $(5,7 \%$ frente a 3,6\% para las bacterias).

Las respuestas a la pregunta « ¿Contienen estos organismos cromosomas/información genética?» se muestran en la tabla I.

Como puede verse, la diferencia conceptual de la per. cepción de los estudiantes sobre los animales, por contraste con otros organismos eucarióticos, en el nivel celular, también resulta aparente en sus respuestas a estas preguntas. En general, los niveles de incertidumbre eran altos ante estas preguntas, a pesar de que eran consistentemente superiores en relación con los cromosomas de lo que lo eran con la información genética.

Para cualquier tipo de organismo, entre el $8 \%$ y el $50 \%$ de estos estudiantes, o bien no sabían si el organismo contenía información genética, o bien creían que no la contenía. Banet y Ayuso (1995) han identificado situa. ciones similares entre los estudiantes españoles de enseñanza secundaria. En general, lo que se deduce de estos datos es que la mitad de estos estudiantes no son conscientes de que todos los seres vivos contienen información genética. Por tanto, ¿qué iđeas tienen acerca de la naturaleza de la información genética?, ¿qué creen que hace?, ¿para qué creen que sirve? Sin embargo, estos hallazgos pueden ser debidos también a que los estudiantes no consideran a todos estos organismos como seres vivos y, por tanto, no les atribuyen características vitales, tales como la posesión de información genética.
Una información más detallada sobre estos hallazgos es presentada en Lewis y otros (1997).

\section{FAMILIALIARIDAD CON LAS NUEVAS TECNOLOGIAS GENÉTICAS Y SU COM- PRENSION}

También se utilizaron sondeos de papel y lápiz para investigar acerca de los conocimientos y comprensión de los estudiantes en esta área. El sondeo La nueva genética proporcionaba una serie de aspectos sobre la tecnología del ADN y pedía a los estudiantes que indicaran de cuáles habían oído hablar. El grado de familiadad đe los estudiantes con las diversas tecnologías viene mostrado en la figura 2 .

Como puede verse, solamente cuatro términos resultaban familiares a más del $50 \%$ de la muestra, y esas cifras no of recen ninguna indicación del nivel de comprensión de los propios términos. Su falta de consciencia tanto acerca de lo que es la terapia genética como del Proyecto del Genoma Humano resulta interesante, dada la cantidad de noticias en los međios de comunicación dedicadas a estos temas justo antes y durante este proyecto. Quizá estas aplicaciones de la tecnología no consiguen captar su interés del mismo modo que to hicieron la ingeniería genética y las pruebas de ADN. O quizá la atención prestada por los medios de comunicación a estas dos últimas tecnologías en los populares programas de ciencia ficción resulta más eficaz que los programas más reales en los que se presenta la terapia genética y el Proyecto de Genoma Humano.

Tabla I

Porcentaje de estudiantes que dijeron que estos organismos contienen cromosomas e información genética ( $n=474$ )

\begin{tabular}{|c|c|c|c|c|c|c|}
\hline & \multicolumn{2}{|c|}{ Sí } & \multicolumn{2}{|c|}{ No } & \multicolumn{2}{|c|}{ No sabe } \\
\hline & Cromosomas & $\begin{array}{l}\text { Información } \\
\text { genética }\end{array}$ & Cromosomas & $\begin{array}{l}\text { Enformación } \\
\text { genética }\end{array}$ & Cromosomas & $\begin{array}{l}\text { Información } \\
\text { genética }\end{array}$ \\
\hline Árboles & 48.5 & 69.1 & 26,8 & 17,2 & 24,7 & 13,8 \\
\hline Mamíferos & 87,5 & 91,6 & 3,0 & 1.8 & 9,5 & 6.6 \\
\hline Heiechos & 40,8 & $\$ 7.7$ & 29,5 & 15.5 & 29.7 & 26,8 \\
\hline Virus & 35,3 & 49,6 & 34,5 & 26,0 & 30,2 & 24,5 \\
\hline Hongos & 40,8 & $\$ 5,9$ & 29,5 & 23,5 & 29,7 & 20.6 \\
\hline Bactcrias & 41,5 & 55,2 & 30,4 & 23,4 & 28,1 & 21,4 \\
\hline Insectos & 82,1 & 88,6 & 4.2 & 3,0 & 13,7 & 8,5 \\
\hline
\end{tabular}


Figura 2

Familiarización con la terminología.

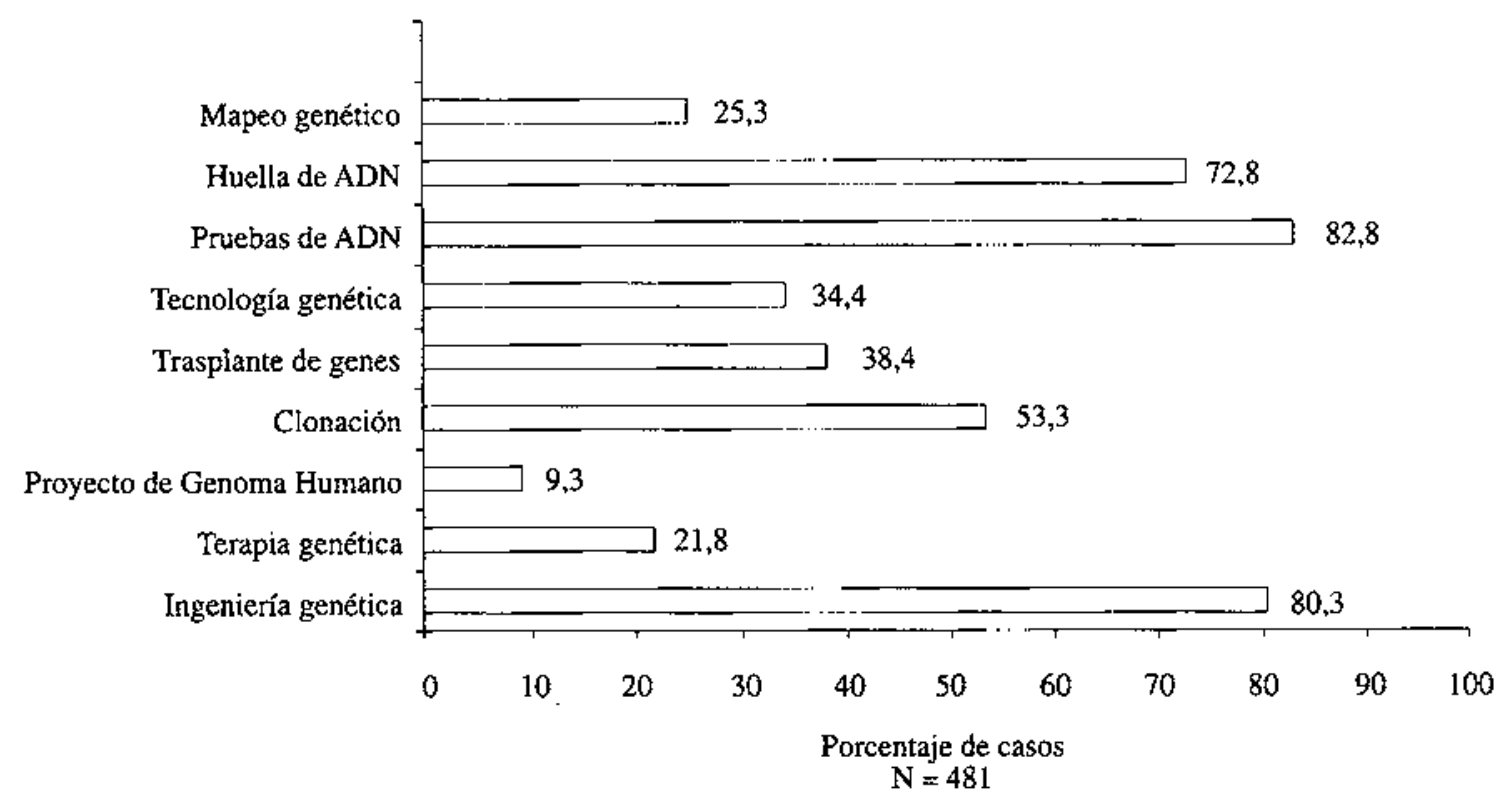

A continuación, el sondeo peđía explicaciones completas acerca de tres de estas tecnologías -ingeniería genética, clonación y pruebas de ADN-y también pedían que explicaran qué es «el código genético». Seguidamente damos un breve resumen de las respuestas.

\section{Ingeniería genética}

$\mathrm{Al}$ preguntarles qué pensaban acerca de la ingeniería genética, un $46 \%$ indicó que era algún tipo de mecanismo, un $25 \%$ sugirió un propósito, mientras que un $8 \%$ đio alguna indicación acerca de su actitud hacia esa tecnología. De los que sugirieron que era un mecanismo, más del $40 \%$ describió la manipulación del material genético con cierta extensión, mientras que un $30 \%$ largo insinuó la manipulación del material genético, pero de forma más ambigua. De los que sugirieron que era un propósito, la mayoría (cerca del $80 \%$ ) dijo que servía para diseñar un organismo a la medida. De los que indicaron una que era actitud, casi el $50 \%$ pensaba que sería una «buena cosa», sin más, y a otro $15 \%$ le parecía que podría ser una buena cosa bajo las circunstancias adecuadas. Al peđírseles que dieran un ejemplo de ingeniería genética, un 35\% mencionó alguno relacionado con la agricultura, mientras que un $53 \%$ dio un ejemplo médico o social. De los que dieron ejemplos médicos o sociales, más de la mitad lo relacionaron con el cambio de sexo u otras circunstancias de un bebé, o con «poner las cosas en su sitio» (terapia genética). También apareció cierta confusión con la cría selectiva.

\section{Clonación}

Al preguntarles qué pensaban acerca de la clonación, el $40 \%$ fue capaz de dar algún tipo de respuesta, De ellos, el $61 \%$ se refirió a copiar genes, ADN o material genético; un 19\% habló simplemente de «copiar», sin ningu na referencia a lo que se estaba copiando; el $7 \%$ confundió la clonación con algún otro aspecto de la tecnología del ADN.

\section{Pruebas de ADN}

Al preguntarles qué pensaban acerca de lo que son las pruebas de $\mathrm{ADN}$, el $51 \%$ de los que respondieron dio una respuesta que sugería cierto grado de comprensión, describiéndolas la mayoría de ellos (72\%) como una inves. tigación más profunda, o bien como la comparación del $\mathrm{ADN}$ o de los fluidos de la gente o de otros organismos. Un 5\% de los que respondieron dio muestras de una actitud frente a las pruebas de ADN, pensando la mayo. ría de ellos que se trataba de una buena cosa. Al pedírseles que dieran un ejemplo, el $28 \%$ dio respuestas relacionadas con la identificación personal, refiriéndose la mayoría a ejemplos forenses.

\section{Código genético}

Solamente el $40 \%$ de los estudiantes dijo haber oído hablar acerca del código genético, siendo capaces la 
mayoría de ellos de decir lo que pensaban que era. De éstos, el $26 \%$ lo describió como un identificador personal o código de barras, afirmando otro $16 \%$ que era un patrón o secuencia de genes, o de ADN, o de bases. Ningún estudiante planteó una relación entre el código y la síntesis de un producto genético, tal como una proteína.

Al preguntar a los estudiantes « ¿Qué has oído acerca de este concepto?», sus respuestas (Tabla II) indicaron la importancia de los medios de comunicación. Es interesante que sea la ciencia ficción, en diversas formas, y no la enseñanza formal, la fuente principal reconocida de información acerca de estas tecnologías. Películas como Parque jurásico o programas populares de televisión como Expediente-X y Enano Rojo (Red Dwarf) fueron mencionados frecuentemente.

Un informe más detallado acerca de este trabajo sobre la familiaridad y la comprensión de la tecnología deI ADN puede encontrarse en Lewis y otros (1997).

\section{OPINIONES Y ACTITUDES SOBRE EL RAS- TREO PRENATAL PARA LA FIBROSIS CIS- TICA}

Es básico en nuestra investigación el principio de que el análisis de cuestiones y opiniones solamente es válido si se explicita el contexto, y de que las opiniones formadas son fuertemente dependientes de ese contexto. Así, las preguntas que interrogan a los estudiantes acerca de hasta qué punto apoyan o son contrarios a afimaciones del tipo «La ley debe prohibir el cambio del contenido genético del ganado» o «A mi entender es aceptable insertar genes de células humanas en los óvulos fertili- zados de Ias ovejas" (Lock y Miles, 1993, p. 269) producirán probablemente respuestas distintas en distintos contextos. Por tanto, la creación de ovejas transgénicas para la producción de insulina humana con el fín de tratar la diabetes puede verse de forma muy distinta a la creación de un ganado genéticamente manipulado cuya carne tiene un mejor sabor o una vida más larga en estado de conservación. Los principios tecnológicos empleados y los tipos de organismos utilizados son similares, pero los contextos son muy diferentes. De modo semejante, la patente de un gen para una pigmentación azul en las rosas con fines de beneficio comercial puede considerarse no problemática. Pero la patente de un gen para la hormona del crecimiento humano por una empresa que persigue comercializar una droga que mejore la altura de jugadores de baloncesto en potencia puede llevar a que la propia tecnología y su subsiguiente patente se consideren de forma bastante distinta. Las opiniones pueden ser incluso más antagónicas si se considerara que tales patentes restringen el tratamiento del enanismo pituitario y, por consiguiente, impiden la reducción del sufrimiento humano.

Si se acepta que las opiniones de las personas y sus actitudes frente a cuestiones planteadas por las nuevas tecnologías genéticas dependen del contexto, aparecen dos consecuencias importantes a partir de este modelo. Primero, sería imprudente generalizar a partir de los resultados obtenidos de preguntas enmarcadas en contextos concretos. Segundo, se debe ser muy meticuloso al clarificar el contexto concreto en el que la pregunta está inmersa. El desarrollo y el análisis de una de las tareas de discusión, La tarea de discusión sobre el rastreo prenatal, utilizada en nuestra investigación, servirá de ejemplo para ilustrar estos puntos. El diseño de Ia tarea, nuestro método de análisis de las discusiones y los hallazgos correspondientes se tratan en detalle en Leach y otros (1996).

\begin{tabular}{|l|c|c|c|}
\hline & Escuela & $\begin{array}{c}\text { Medios } \\
\text { de comunicación }\end{array}$ & Orros \\
\hline $\begin{array}{l}\text { Ingeniería genética } \\
(n=338)\end{array}$ & $49 \%$ & $68 \%$ & $2 \%$ \\
\hline $\begin{array}{l}\text { Clonación } \\
(n=220)\end{array}$ & $33 \%$ & $76 \%$ & $3 \%$ \\
\hline $\begin{array}{l}\text { Prueba de ADN } \\
(n=331)\end{array}$ & $35 \%$ & $77 \%$ & $2 \%$ \\
\hline
\end{tabular}


La tarea se centraba en el rastreo prenatal de la fibrosis cística (FC). Se trata de un desorden hereditario de tipo autosómico y homozigótico. Esto quiere decir que tal situación solamente se dará en personas que han heredado dos copias del alelo $\mathrm{FC}$-una de cada progenitor. Una persona que hereda solamente un alelo $\mathrm{FC}$ (por ejemplo, de un sólo progenitor) no se verá afectada, pero será capaz de pasar el alelo FC a sus hijos. A tales personas se les conoce como portadores de FC. Áquellos que heredan dos copias del alelo FC experimentarán los síntomas de tal situación desde su nacimiento. Estos síntomas comprenden un exceso de producción de mucus viscoso en los pulmones y en el sistema digestivo, con resultado de sufrir problemas en la respiración y en la digestión. Una agotadora fisioterapia diaria puede aliviar los problemas respiratorios, pero aun así persistirá un alto riesgo de infección pulmonar. Se pueden tomar enzimas y otras medicinas para reducir los problemas digestivos. Pero, a pesar de estas medidas, la esperanza de vida de los individuos con $F C$ se reduce a un margen de entre veinte y cuarenta años.

Algunas investigaciones recientes se han centrado en el desarrollo de una terapia genética somática para el tratamiento de la FC. En teoría, si pudieran insertarse los aleios funcionales en las células epiteliales que recubren los pulmones, estas células funcionarían normalmente. En la práctica, aunque se haya demostrado que ello es posible, la eficacia de dicha terapia es limitada y de corta duración, y no sirve para los desórdenes digestivos. La terapia genética está, realmente, en un estadio experimental.

El rastreo genético de la condición de portador de FC se Ileva a cabo utilizando células epiteliales de la cavidad bucal recogidas mediante un simple lavado de boca. Alrededor del $90 \%$ de los casos de alelos afectados puede ser identificado por este procedimiento. Existen, evidentemente, cuestiones éticas que surgen de la disponibilidad del rastreo genético de la condición de FC.

- ¿Deberían someterse al rastreo todos los individuos, como una cuestión de normativa?

- Si no se deben someter a rastreo todos los individuos, ¿quiénes deben seleccionarse para serlo?

- ¿Quién debe tomar la decisión de si un individuo debe someterse a rastreo o no?

- ¿Quién tiene derechos sobre la información obtenida del rastreo?

- ¿Se debería impedir que las personas afectadas tuvieran hijos?

El rastreo de la condición de $\mathrm{FC}$ también puede realizarse sobre el feto, lo cual ofrece información tanto sobre si el bebé sufrirá la enfermedad como si será portador de la FC. Ello genera otro conjunto de cuestiones.

- El rastreo prenatal es desagradable para la madre.
- Existe un pequeño riesgo de aborto espontáneo asociado con el rastreo prenatal.

- Un resultado negativo puede ayudar a disipar temores y a reducir la incertidumbre.

- El rastreo prenatal tiene solamente un $90 \%$ de eficacia para resultados negativos.

- El rastreo prenatal puede dar indicaciones de que el feto será portador de la FC.

- El rastreo prenatal puede dar indicaciones de que el feto sufrirá la FC.

- La identificación positiva de la FC en el feto plantea la cuestión de la futura calidad de vida del niño.

- La identificación positiva de La FC en el feto suscita la cuestión del aborto.

- Existe una futura posibilidad de que haya progresos en el tratamiento de la FC.

No obstante, la mayoría de los jóvenes, al final de sus once años de enseñanza obligatoria no saben nada acerca de la fibrosis cística, de la probabilidad de haberla heredado de un progenitor afectado, de la posibilidad de tratamiento disponible o de las consecuencias de la enfermedad sobre aquéllos que la sufren. Por consiguiente, no estarán en condiciones de apreciar los problemas y cuestiones que acabamos de enumerar. Se les deberá suministrar la información adecuada para que puedan alcanzar una opinión razonada de si el rastreo prenatal constituye, según ellos, una acción razonable en circunstancias particulares.

Para la presente investigación, tal información se les suministró mediante una grabación en vídeo de 15 minutos especialmente realizada con ese fín, y se les present 6 a los estudiantes implicados. La primera tarea de los investigadores fue comprobar que el grupo de estudiantes con el que estaba trabajando había entendido los aspectos importantes acerca de la FC y del rastreo, mencionados en el vídeo. Ello se hizo a través de la discusión entre estudiantes de un cierto número de afirmaciones -algunas ciertas y otras falsas- que se les suministró en fichas. Después, el investigador planteaba el estatus de cada afirmación con el fin de asegurarse de que los miembros del grupo tenían una buena comprensión de cada punto. Estas afirmaciones se muestran a continuación:

- «Creo que la persona que, en el vídeo, hace la fisioterapia al que sufre la FC debería llevar una mascarilla.»

- «Ya tenemos un hijo con FC, por tanto estamos seguros de que el próximo estará perfectamente.»

- «Acabo de enterarme de que soy portador de la FC. Pero todavia hay posibilidades de tener hijos normales, »

- «Me gustaría someterme a una prueba para ver si soy portador de la $\mathrm{FC}$, pero te tienen que meter una aguja.» 
- «Puesto que ambos somos portadores, todavía hay una probabilidad de 1 a 4 de que nuestro próximo hijo tenga FC."

- «No será fantástico cuando una pulverización nasal me cure la FC y no tenga que sufrir todo este tratamiento.»

A continuación, se les presentó una discusión de 10 minutos grabada en cinta entre los miembros de una pareja joven -cada uno de ellos ya identificado como portador de $\mathrm{FC}$ - que estaban considerando si deberían o no someter a su hijo aún en gestación a las pruebas de FC. Esta grabación suscitaba las cuestiones enumeradas más arriba relacionadas con el rastreo prenatal. Así, los grupos estaban ahora en situación de tener una discusión informada acerca de si la joven pareja debería hacer que su futuro hijo pasara las pruebas o no.

Los resultados detallados de la Tarea de discusión sobre el rastreo prenatal se discuten en Leach y otros (1996), pero merece la pena destacar aquí algunos puntos importantes:

- Casi todos los estudiantes habían captado los principales puntos establecidos en el vídeo y fueron capaces de mostrar su comprensión a través de sus comentarios en cada una de las seis declaraciones dadas líneas más arriba.

- A pesar de que la calidad general de las discusiones fue variada, algunos grupos mantuvieron discusiones muy bien informadas, identificando una serie de cuestiones y evaluando cada una dentro de una serie de circunstancias; en otras, solamente se identificó un pequeño número de cuestiones y cada una se presentó como positiva o como negativa sin referencia alguna a los factores de contexto; la mayoría de las discusiones se desarrollaron en puntos intermedios entre estos dos extremos.

- A la mayoría de los estudiantes les parecía que la joven pareja debería hacerse la prueba prenatal de la FC para poder tomar en consideración la posibilidad del aborto o prepararse para el nacimiento de un niño con FC.

- Los riesgos asociados con la prueba y la inherente incertidumbre de un resultado negativo se consideraban insignificantes frente a las ventajas de hacerse la prueba.

- Los estudiantes que pensaban que la pareja no debería hacerse la prueba prenatal tendían a justificar su posición en términos de una actitud negativa hacia el aborto.

- A la mayoría de los estudiantes les parecía que el aborto no era adecuado para un feto con $\mathrm{FC}$, una vez formulado su juicio acerca de la calidad de vida de los que sufren $\mathrm{FC}$.

- Un número significativo de estudiantes reconocía la posibilidad de futuros avances en la terapia genética.

- Unos pocos estudiantes consideraban los avances en la terapia genética como demasiado distantes y creían que la calidad de vida de los que sufren FC era suficientemente baja como para valer la pena el aborto.

\section{OTROS HALLAZGOS E IMPLICACIONES PARA LOS CURRÍCULOS ESCOLARES Y LA ENSENANZA}

Las evidencias obtenidas en esta investigación sugieren que la base genética de la vida es escasamente entendida por los estudiantes ingleses. Han obtenido evidencias semejantes de los estudiantes españoles Banet y Ayuso (1995) y Ayuso y otros (1996). Muchos estudiantes ingleses, por ejemplo, creían que solamente contenían algún tipo de información genética los animales y que tal información no estaba presente en organismos tales como los árboles, los helechos, las bacterias y los hongos. Unos pocos estudiantes tenían alguna idea acerca de que está presente una información genética idéntica en todas las células somáticas de un organismo multicelular individual, siendo una regulación adecuada la que determina las distintas estructuras y funcionamiento de los distintos tipos de células. Menos de un estudiante de cada cinco mostró una verdadera comprensión acerca del código genético, y ni un sólo estudiante de nuestra muestra relacionó el código genético con un producto genético tal como una proteína. Muy pocos estudiantes estaban familiarizados con las características, o formas de herencia, de enfermedades genéticas como la fibrosis cística o la enfermedad de Huntington.

Teniendo en cuenta estos puntos, sería ilusorio esperar un alto nivel de comprensión de las tecnologías genéticas. Las discusiones informadas acerca de las cuestiones que implicaban el rastreo genético - prenatal o de otra índole-, la tecnología de ADN recombinante, la identificación por huella de ADN, etc. resultarian, por tanto, imposibles. No obstante, resultó sorprendente comprobar que a la mayoría de los estudiantes se les podía proporcionar fácilmente, en poco tiempo, la suficiente información para poder realizar una discusión razonada, centrada en las cuestiones suscitadas por estas tecnologías. Ello sugiere la necesidad de materiales curriculares bien investigados que permitan a los estudiantes desarrollar una mejor comprensión de la genética básica y la capacidad para evaluar tales cuestiones de forma útil.

Existe también una necesidad de relacionar áreas del currículo que se enseñan a menudo en la actualidad en distintos momentos. La estructura de la célula se suele incluir en una etapa relativamente elemental, dejando la genética, frecuentemente, para los últimos cursos; el crecimiento, la división y diferenciación celular ocupan un lugar intermedio. Hay una clara necesidad de interrelacionar estos aspectos de forma que las ideas sobre la transferencia de la información genética de una célula a otra se entienda con mayor claridad.

El desarrollo de la «nueva genética» y de otros aspectos de la biotecnología han sido muy rápidos en los últimos años. El currículo de ciencias en Inglaterra y Gales no ha mantenido el mismo ritmo que estos cambios -es más, la introducción de un Currículo Nacional, en realidad, ha invertido la tendencia según la cual se estaba dando un mayor énfasis, en los programas, a la biotecnología. Si la ciencia se ha de justificar en la enseñanza obligatoria sobre bases utilitarias y democráticas, habrá que encon- 
trar oportunidades para discusiones bien informadas acerca de la implicaciones que surgen de las nuevas tecnologías genéticas, brevemente esbozadas al principio de este artículo. Si tales discusiones deben hacerse sobre la base de una buena información, quienes desarollen los currículos y los profesores deben proporcionar a los estudiantes la información adecuada acerca de los contextos concretos en los que esas tecnologías se pueden aplicar. De este modo los estudiantes pueden adquirir experiencia para sopesar las cuestiones sociales y éticas implicadas en la consecución de un punto de vista razonado.

\section{NOTA}

- Las escuelas en Escocia se rigen por una legislación gubernamental bastante diferente y siguen un currículo distinto.

\footnotetext{
* Ponencia presentada en el V Congreso Internacional sobre Investigación en la Didáctica de las Ciencias (Murcia, 10 a 13 de septiembre de 1997). Ha sido traducida del inglés por J. Tortella y revisada por Óscar Barberá.
}

\section{REFERENCIAS BIBLIOGRÁFICAS}

AMERICAN ASSOCIATION FOR THE ADVANCEMENT OF SCIENCE. (1989). Science for all Americans. Washington, DC: AASS.

AYUSO, E., BANET, E. y ABELLÁN, T. (1996). Introducción a la genética en la enseñanza secundaria y el bachillerato. II. ¿Resolución de problemas o realización de ejercicios? Enseñanza de las Ciencias, 14(2), pp. 127-142.

BANET, E. y AYUSO, E. (1995). Introducción a la genética en la enseñanza secundaria y el bachillerato. I. Contenidos de enseñanza y conocimientos de los alumnos. Enseñanza de las Ciencias, 13, (2), pp. 137-153.

DEPARTMENT OF EDUCATION AND SCIENCE. (199J) Science in the National Curriculam (1991), Department of Education and Science and the Welsh Office. Londres: HMSO.

DRIVER, R., LEACH, J., MILLAR, R. y SCOTT, P. (1996). Young People's Images of Science, Buckingham: Open University Press.

EUROPEAN UNION. (1993), Growth, Competitiveness and Employment. Informe gubernamental considerado por el Consejo de Europa, diciembre de 1993.

HOUSE OF COMMONS SCIENCE AND TECHNOLOGY COMMITTEE. (1995). Third Report - Human Genetics: The Science and its Consequences, Vol. 1. Londres: HMSO.
LAYTON, D., JENKINS, E., MACGILL, S. y DAVEY, A. (1993). Inarticulate science? perspectives on the public understanding of science and some implications for science education. Driffield: Studies in Education Ltd.

LEACH,J.T.,LEWIS, J. M., DRIVER, R. y WOOD-ROBINSON, C. (1996). Opinions on and attitudes towards genetic screening: A - Prenatal screening for cystic fibrosis, Working Paper 5 of the Young People's understanding of, and attitudes to, "The New Genetics" project. University of Leeds, Centre for Studies in Science and Mathematics Education, Learning in Science Research Group.

LEWIS, J.M., DRIVER, R. LEACH, J. T. y WOOD-ROBWNSON C. (1997). Understanding of basic genetics and DNA technology, Working Paper 2 of the Young People's understanding of, and attifudes to, "The New Genetics" Project. University of Leeds, Centre for Studies in Science and Mathematics Education, Learning in Science Research Group.

LEWIS, J. M., DRIVER, R. LEACH, J. T. y WOOD-ROBINSON, C. (en preparación). Understanding of the genetic cells, Part B: The Written Probes, Working Paper 4 of the Young People's understanding of, and attitudes to, "The New Genetics" Project. University of Leeds, Centre for Sudies in Science and Mathematics Education, Learning in Science Research Group. 
LOCK, R., y MILES, C. (1993). Biotechnology and genetic engineering: students knowhedge and attitudes. Journal of Biological Education, 27(4), pp. 267-272.

MICHIE, S., DRAKE, H., BOBROW, M. y MARTEAU, T. (1995). A comparison of public and professional attitudes towards genetic developments. Public Understanding of Science, 4, pp. 243-353.

MILLAR, R. (1996).Towards a science curriculum for public understanding. School Science Review, 77(280), pp. 7-18.

NATIONAL CURRICULUM COUNCIL. (1993) Teaching Science and Key Stages 3 and 4. Londres: HMSO.

OSBORNE, R. J. y GILBERT, J. K. (1980). A method for investigating concept understanding in science. European Journal of Science, 2, pp. 311-321.

ROYAL SOCIETY. (1985). The Public Understanding of Science. Londres: The Royal Society.

TURNEY, J. (1995). The public understanding of genetics where next? European Journal of Genetics and Society, $1(2)$, pp. $5 \cdot 20$.
WOOD-ROBINSON, C. (1994). Young people's ideas about inheritance and evolution. Studies in Science Education, 24, pp. 29-47.

WOOD-ROBINSON, C. (1995). Children's biological ideas: knowledge about ecology, inheritance and evolution, pp. 111-130, en Learning Science in the Schools: Research Reforming Practice, editado por Glynn, S.M. y Dutit, R. Mahwah. Nueva Jersey: Lawrence Erlbaum Associates.

WOOD-ROBINSON, C., LEWIS, J., DRIVER, R. y LEACH, J. (1996). Rationale, design and methodology: Working Paper I of the Young people's understanding of, and attitudes to, "The New Genetics» project. University of Leeds, Centre for Studies in Science and Mathematics Education, Leaming in Science Research Group

WOOD-ROBINSON, C., LEWIS, J., DRIVER, R. y LEACH, J. (en preparación). Students» understanding of basic genetics - evidence from small group discussions: Working Paper 3 of the Young people's understanding of, and attitudes to, «The New Genetics» project. University of Leeds, Centre for Studies in Science and Mathematics Education, Learning in Science Research Group 


\section{Apéndice I}

Las ciencias en el Currículo Nacional (1991)

Esta versión del Currículo Nacional se presentó al Parlamento en diciembre de 1991. Los contenidos de la Orden relacionados con la tercera etapa clave tuvieron efecto desde el 1 de agosto de 1992, por lo que afectaba a todos los alumnos de esa etapa clave. Los contenidos de la Orden relacionados con la cuarta etapa clave tuvieron efecto desde el I de agosto de 1992, por lo que afectaba a todos los alumnos del primer año de esa etapa clave; y el 1 de agosto de 1993, por lo que afectaba al resto de los alumnos. Esta versión de las ciencias dentro del Currículo Nacional afectaba a los estudiantes analizados en este estudio y se utilizó, junto con atras consideraciones, como base para el diseño de los instrumentos de investigación.

A continuación se presentan las secciones relevantes para la genética contenidas en Ciencia en el Curriculo Nacional (1991).

ETAPA CLAVE 3 (Para alumnos de edades de 11 a 14).

En la introducción al Programa de Estudio:

La aplicación de la ciencia: A los alumnos debe ofrecérseles la posibilidad de desarrollar su conciencia acerca de la importancia de la ciencia en la vida cotidiana, y progresando a partir de experiencias previas, a partir de su conocimiento y comprensión creciente y de su cada vez mayor madurez, de estudiar cómo se aplica la ciencia en una diversidad de contextos. Deberán analizar los beneficios y las desventajas de aplicar las ideas científicas y tecnológicas a sí mismos, a la industria, al entomo y a la comunidad. Deberán empezar a tomar decisiones y a formular juicios basados en su conocimiento científico de cliestiones que afectan a la salud y al bienestar personales, a la seguridad y ai cuidado del entorno. A través de este estudio, deberán empezar a entender de qué forma la ciencia modela $e$ influye en ella la caljdad de sus vidas.

Objetivo 2: Vida y procesos vitales

Los alumnos deberían desarroliar el conocimiento y comprension de:

a) los procesos vitales y la organización de los seres vivos;

b) la variación y los mecanismos de la herencia y de la evolución.

\section{PROGRAMA DE ESTUDIO}

Los alumnos deberían explorar e investigar cómo están organizadas normalmente las plantas con flores y los mamíferos en los riveles celular y macroscópico. Deberían estudiar los procesos vitales [...], reproducción, [...]

[...] Deberian calibrar e investigar las diferencias entre tos individuos de una gama de seres vivos, prestando atención a su bienestar. Deberian extraer, de los datos, las tendencias y normas, y considerar las causas genéticas y ambientales de la variación y de la extinción. Deberían estudiar cómo se transmite la información en forma de genes de una generación a la siguiente. Se les debería introducir a la idea de la cría selectiva.

\section{FORMULACIÓN DE OBJETIVOS}

Los alumnos deberian:

\section{NIVEL 3}

a) conocer los procesos vitales básicos que son comunes a los humanos y a otros animales.

Ejemplos: Identificar procesos tales como [...] la reproducción en tanto que es propia de sí mismos y común con los animales familiares.

\section{NIVEL 5}

b) sabet qué información, en forma de genes, se pasá de una generación a la siguiente.

Ejemplo: Utilizar información de una familia extensa (de humanos, de cobayas, de conejos) para mostrar que se puede heredar un carácter.

\section{NIVEL 6}

a) ser capaces de relacionar estructura con funciớn, en las células vegetales y animales.

Ejemplos: Explicar cómo la estructura de la neurona permite que los impulsos nerviosos se transmitan a una gran distancia y cómo facilita la estructura de una célula en empalizada la fotosíntesis de una hoja. 
c) saber que la variación en los organismos vivos tiene causas tanto genéticas como ambientales.

Ejemplo: Explicar algunas posibles causas de la variación en el peso de los humanos al nacer.

\section{NIVEL 7}

c) entender en qué forma puede la cría selectiva producir beneficios económicos y contribuir a mejorar los rendimientos.

Ejemplo: Describir cómo se han producido las modernas variedades de trigo a partir de especies salvajes, para proporcionar mayores rendimientos, incrementar la resistencia a las enfermedades y tener periodos de recolección más cortos.

\section{ETAPA CLAVE 4 (Para alumnos de edades de 14 a 16)}

En esta etapa de escolarización, tos alumnos pueden elegir un curso que les acredite para un diploma doble en ciencias o un curso alternativo que les acredite para un diploma simple en ciencias. En en el Currículo Nacional (1991), en relación con la genética, no existen diferencias entre el Programa de Estudio y las Formulaciones de Objetivos para el curso doble o simple en ciencias.

En la introducción al Programa de Estudio:

La aplicación y las implicaciones económicas, sociales y tecnológicas de la ciencia: Se debe dar a los aìumnos la oportunidad de desarrollar su conciencia acerca de la ciencia en fa vida cotidiana. Progresando a partir de experiencias previas, a partir de su conocimiento y comprensión crecientes y de su cada vez mayor madurez, deberían estudiar cómo se aplica la ciencia en una diversidad de contextos [...] Deberían utilizar sus conocimientos y preparación científica para tomar decisiones y emitir juicios que afecten a la salud y a la seguridad personales. Deberían analizar los efectos de los desartollos científicos y tecnológicos [...] sobre los individuos, las comunidades y los entornos. A través de este estudio, deberían empezar a entender el poder y las limitaciones de la ciencia para resolver los problemas industriales, sociales y ambientales, y para reconocer la concurrencia de prioridades.

La naturaleza de las ideas científicas: Se debería dar a los alumnos la oportunidad de desarrollar sus conocimientos y comprensión de cómo cambian las ideas científicas a lo largo del tiempo y de cómo su naturaleza y el uso que de ellas se hace son afectadas por Ios contextos sociales, morales, espirituales y culturales en los que se desarrollan. De este modo, deberán empezar a darse cuenta de que, si bien la ciencia es una manera importante de pensar acerca de la experiencia, no es la única.

\section{Objetivo 2: Vida y procesos vitales}

Los alumnos deberían desarrollar los conocimientos y la comprensión de:

a) los procesos vitales y la organización de los seres vivos;

b) la variación y los mecanismos de la herencia y de la evolución.

\section{PROGRAMA DE ESTUDIO}

En el contexto del estudio de los principales órganos humanos, se deberían considerar los factores asociados a un estilo de vida saludable y a ejemplos de tecnologías utilizadas para promover, mejorar y mantener la calidad de vida. Deberían considerar la interacción de los factores genéticos y ambientales (incluidas las radiaciones) en la variación. Se debería introducir el concepto de gen como parte de una molécula de ADN, y se debería estudiar de qué forma es capaz el ADN de duplicarse a sí mismo y de controlar la síntesis de las proteínas mediante un código de bases. Utilizando el concepto de gen, se debería explorar los principios básicos de la herencia en plantas y animales y su aplicación para la comprensión de cómo se determina el sexo en los seres humanos y cómo se pueden heredar algunas enfermedades. Utilizando fuentes que den una gama de perspectivas, se debería tener la oportunidad de considerar los principios básicos de la ingenieria genética, por ejemplo, en relación con la producción de medicinas y hormonas, así como tener conciencia de cualquier consideración ética que tal producción implica. Se deberían considerar las evidencias de la evolución y explorar las ideas acerca de la variabilidad y de la selección que conducen a la evolución y a la cría selectiva. Se deberían considerar los aspectos sociales, económicos y éticos de ła clonación y de la cría selectiva.

\section{FORMULACIÓN DE OBJETIVOS}

Además de aquellas Formulaciones de Objetivos para los Niveles 4 a 7 , identificados más arriba para la Etapa Clave 3 , Jos alumnos deberían:

\section{NIVEL 8}

b) saber cómo se transmite la información genética de cétula a célula y de generación a generación, mediante la división celular.

Ejemplos: Serie de fotografías que muestre cómo aparecen primero los cromosomas y a continuación cómo se reparten igualmente en las células hijas, durante la mitosis, y cómo los pares de cromosomas se dividen equitativamente durante la meiosis.

c) entender los principios de un cruce monohíbrido con alelos dominantes y recesivos.

Ejemplo: Explicar o predecir las proporciones entre los fenotipos y genotipos en los cruces monohibridos simples, por ejemplo, entre diferentes linajes de Drosophila. 


\section{NIVEL 9}

b) entender los diferentes orígenes de la variación genética.

Ejemplo: Explicar cómo tiene lugar la variación genética barajando cromosomas y por mutación de genes.

c) entender las relaciones entre variación, selección natural y éxito reproductivo en los organismos y el significado de estas relaciones para la evolución.

Ejemplos: Explicar cómo evolucionaron ciertos organismos como los pinzones de las islas Galápagos y las polillas moteadas británicas para adaptarse a los nichos ecológicos que ocupan en la actualidad.

\section{NIVEL 10}

b) entender cómo se replica el ADN y cómo controla la síntesis de las protefnas mediante un código de bases.

Ejemplo: Destacar la naturaleza autorreplicadora del $A D N$ y cómo la secuencia de bases puede codificar los aminoácidos en una proteina.

c) entender los principios básicos de la ingeniería genética, de la cría selectiva y de la clonación, y cómo estas técnicas suscitan cuestiones sociales y éticas.

Ejemplos: Explicar cómo puede obtenerse la insulina humana a partir de bacterias manipuladas por ingeniería genética; discutir las cuestiones que se suscitan para la sociedad debido a la posibilidad de corregir desórdenes genéticos humanos. 


\section{Apéndice II}

\section{A. Genética básica}

1. Lenguaje (conocimiento de la terminología):

a) têrminos relacionados con la genética básica;

b) gana de organismos.

2. Localización (relación entre estructuras):

a) localización de los genes dentro de los organismos;

b) localización de los genes dertro de las células;

c) relación entre estrutcturas, desde el gen hasta el organismo completo;

d) ámbito de la mitosis (células somáticas);

e) ámbito de la meiosis (células germinales).

3. Función de los genes (expresión/replicación):

a) código de los genes para las proteínas;

b) la información genética debe copiarse para ser transferida a las nuevas células durante la división celular.

4. Mecanismo de la acción genética (conmutadores/códigos/variación):

a) puede existir un único gen en diferentes formas (alelos) y puede producir diferentes fenotipos que resulten en variabilidad;

b) la expresión genética depende del entorno (interno y externo) para «desencadenar» los conmutadores;

c) el "código genético» es universal -el mismo en todos los organismos;

d) la división celular por mitosis (células somáticas, para el crecimiento) da como resultado nuevas células que contienen un número idéntico de cromosomas y exactamente la misma información genética;

e) la división celular por meiosis (células germinales, para la reproducción) da como resultado nuevas células que contienen la mitad de cromosomas y diferente información genética (incrementa la variación);

f) la fertilización genera continuidad (la información genética pasa de padres a hijos) y variación (mezcla de alelos).

5. Semejanzas/diferencias entre célunlas:

- Dentro de un mismo organismo

a) los diferentes tipos de células somáticas contienen todas ellas la misma información;

b) la diferente estructura/función de las células (células somáticas) se consigue por la activación diferenciada de genes (concepto de conmutador genético);

c) las células germinales contienen diferente información genética incluso a pesar de ser del mismo tipo de célula.

- Entre organismos dentro de una misma especie

a) la producción de células germinales conilleva variación; ta combinación aleatoria de células germinales en la fertilización ileva a una variación aún mayor; el resultado es que las células de diferentes organismos siempre contienen información genética diferente (la excepción de los gemelos monozigóticos se debe a la fertilización del mismo óvulo);

b) los alelos son la fuente de variación;

c) las presiones de selección alterarán la frecuencia de las distintas mutaciones dentro del conjunto de genes (verbigracia, alteran la frecuencia de los distintos alelos).

- Entre diferentes especies

a) todos los organismos contienen información genética (procarióticos/eucarióticos, plantas/animales);

b) la información genética está siempre codificada en forma de ácidos nucleicos;

c) el código es interpretado o «leídon (traducido) de la misma forma en todos los organismos;

d) la información genética se copia y se transmite durante la división celular en todos los organismos.

\section{B. Tecnología del ADN}

1. Técnicas:

a) têrminos utilizados para describir las técnicas;

b) comprensión de los términos.

2. Aplicaciones:

a) reales o potenciales. 